\title{
Flow Pattern and Stress Distribution around Three Spur Dike in Ninety Degree Bend
}

\author{
S. A. Salamatian, M. Forghani, and M. Karimaee Tabarestani
}

\begin{abstract}
Spur dikes are structures that often be utilized for three main purposes, such as increasing water level, river bank protection, and sedimentation. This type of construction's use for a long time shows its usefulness and good features. Experimental investigation on flow pattern around 3 spur dikes in clear water with 2-D velocimeter has been achieved. These experiments have been accomplished in 3 different occasions of series of spur dikes (the first spur dike at 30 degrees, 45 degrees, and 90 degrees). In each experiment, flow pattern has been measured from 20 degrees before and 20 degrees after spur dike. Also bed topography has been determined in all cases and in obvious distance. In this paper bed shear stress, exist vortexes and flow pattern has been surveyed and analyzed, furthermore interaction between flow pattern and bed variations has been mentioned. Results showed that by increasing the position of spur dikes to the downstream the length of separation zone decreases, and also the width of separation zone remain almost constant.
\end{abstract}

Index Terms-Bank protection, flow pattern, sedimentation, spur dikes, vortex, water level.

\section{INTRODUCTION}

Spur dikes are structures that often be utilized for three main purposes, increasing water level, river bank protection, and sedimentation. This type of construction's use for a long time shows its usefulness and good features. In alluvial bed rivers, placement of this type of structure results in bed scouring. This process poses a very serious danger for the stability of structures. Hence, many researchers conducted experiments on flow and scouring around spur dikes. One of the main parameter influencing the scouring process is flow velocity. It is believed that better understanding of scouring near spur dikes depends on studying flow characteristics. Most of researchers investigated on maximum of scour depth around spur dike in straight channel, whereas a little investigation have been achieved about flow pattern around the spur dike especially when the spur dikes located in the bend.

For instance, Tingsanchali and Maheswaran in 1983, surveyed flow pattern and bed shear stress in Straight channel with solid bed by numerical method [1]. Also, Giri and Shimizu (2004) have studied the flow pattern and bed topography around a spur dike in meandering channels with sandy bed [2]. Rajaratnam and Nwachukwu (1983) have

Manuscript received March 11, 2015; revised October 27, 2015

S. A. Salamatian and M. Karimaee Tabarestaniare are with Shahab Danesh Institute of Higher Education, Qom, Iran (e-mail: Amin.salamatian@gmail.com, M.karimaee@aut.ac.ir).

M. Forghani is with Tarbiat Modares University, Tehran, Iran (e-mail: m.forghani@mekpco.com). surveyed flow pattern around the single spur dike in rigid bed and straight conduit [3]. Molians et al. (1998) have investigated bed shear stress around the structures with vertical wall [4]. Ghodsian \& moosavi (2005) have studied the scouring around single spur dike at 90 degrees bend with solid bed [5]. Soliman et al. (1997) prepared 2-D computational method for studying the effects of spur dikes on Scouring in Nile River [6]. They investigated effect of different lengths and distances of spur dikes on the level of the water surface and velocity components. Hoseini (2006) generated a numerical model around a single spur dike at 90 degrees bend with rigid bed at 90 degrees bed without spur dike [7]. He has achieved that the position of the vortices which occur at downstream of spur dike were different in water surface and near the bed. Also, he showed that in the constant discharge by displacing position of spur dikes toward the downstream of the 90 degrees bend, shear stress around spur dikes increased.

Ghodsian et al. (2007) studied flow pattern around single spur dike at the bend with rigid bed [8]. He has conducted his experiences in 3 different discharge $(15,30 \& 45 \mathrm{lit} / \mathrm{sec}) 3$ different lengths of spur dike $(5,10 \& 15 \mathrm{~cm})$ and 5 different positions of spur dike location $(15,30,45,60,75$ degrees arch) and has been achieved to these results briefly:

1) Increasing the amount of discharge doesn't have any effect on the position of maximum shear stress

2) Maximum amount of shear stress through the bend is variable between 1.2 up to 0.9 amount of the upstream shear stress.

Forghani and Ghodsian (2007) have investigated on flow pattern and bed scouring around a single spur dike at $90^{\circ}$ bend channel [9]. They have achieved that the depth of scour hole decreases by displacing the position of spur dikes toward the end of bend.

Regarding to lack of information about flow pattern around the spur dike at bend, the present paper attends to investigate two-dimensional flow field in vicinity of 3 spur dikes in curved channel with sandy bed under a clear water regime, using the $2 \mathrm{D}$ velocimeter.

\section{EXPERIMENTATIONS}

Experiments in a curved channel were carried out at the Hydraulic Laboratory of Tarbiat Modares University, Tehran, Iran. The main channel consisted of a $7.1 \mathrm{~m}$ long upstream and a $5.2 \mathrm{~m}$ long downstream straight reaches. A $90^{\circ}$ channel bend was located between the two straight reaches. The channel was of rectangular cross section $0.6 \mathrm{~m}$ width, $0.7 \mathrm{~m}$ height with $2.5 \mathrm{~m}$ radius of bend to centerline. Fig. 1 shows a schematic view of flume. The bed and sides of flumes were 
made of glass supported by metal frame. Measurement of discharge was done by a calibrated orifice set in the supply pipe. Depth of flow and bed profile was measured by a digital point gauge having an accuracy of $\pm 0.01 \mathrm{~mm}$. A sluice gate was located at the end of the main channel to control flow depth. Uniform sediment with a median size of $\mathrm{d}_{50}=1.28 \mathrm{~mm}$ was used with a thickness of $0.35 \mathrm{~m}$ and covered the total length of flume. Spur dikes were made of Plexiglas with a thickness of $1 \mathrm{~cm}$ and length of $9 \mathrm{~cm}$ fixed to the side of flume. Spur dikes were located at $15^{\circ}$ interval along the bend. The distance between the series of spur dikes was $5^{\circ}$ (see Table I). Experiments were performed near threshold condition in straight channel i.e. $0.9<\mathrm{U} / \mathrm{U}_{\mathrm{c}}<1$ ( $\mathrm{U}$ is approach velocity and $U_{c}$ is critical velocity for sediment movement). Velocities were measured by 2D velocimeter P-EMS model at eleven radial sections which included twelve transversal and seven vertical points (see Table I and Fig. 2). Velocity in each point was measured for $20-30 \mathrm{sec}$ and then time averaged value was calculated. The measuring sections were selected radially at every $1.25^{\circ}$ to $10^{\circ}$, depending on distance from spur dike. The flow visualization was carried out by injecting potassium permanganate with a thin ribbon, then photographing and videotaping its trace. Initially, the bed surface was smoothed by a plate attached to the carriage mounted on the channel, then inlet valve was opened slowly, the discharge increased to a predetermined value so that no scour occurs at the straight reaches of the flume. At the end of experiments, the topography of bed was measured at grids of $2 * 2.5 \mathrm{~cm}$ around spur dike nose and at grids of $2 * 12 \mathrm{~cm}$ in the other sections.

Regarding the equilibrium of scour hole achieved after 25 hours in each experiment, a series of initial experiments have been done to specifying the start time for assigning the flow pattern. Based on existing information from results of initial experiments, variation of average velocity components $(\bar{u}, \bar{v})$, and also velocity resultant $\left(\bar{w}=\sqrt{\bar{u}^{2}+\bar{v}^{2}}\right)$ components, reaches to its minimum amount (about 5\%) approximately after the 18th hour of experiment. In other point of view, achieved results from initial experiments indicate that amount of velocity in different points is constant after 18 hours. So, a 19th hour after beginning of experiment has been chosen to be as start of recording velocity samples.

Because some record of flow pattern elapse long time (about 15 hours), for stopping variation of nominal bed topography, in these experiments freezing method has been used. In this way after finishing experiment ( 25 hours) and bed derange, compound of concrete glue and other additive materials have been poured on the scoured bed. This act stabilized the bed shape after doing experiment again up to 24 hours after starting experiment again. After stabilizing the bed, experiment has been done one more time and recording velocity was continuing.

TABLE I: EXPERIMENTS CHARACTERISTICS

\begin{tabular}{|c|c|l|c|}
\hline & $\begin{array}{c}\text { Position of spur } \\
\text { dikes }\end{array}$ & $\begin{array}{l}\text { Approach flow depth, h } \\
(\mathrm{cm})\end{array}$ & 10.8 \\
\hline Situation no.1 & 30,35, and 40 & Froude number, Fr & 0.359 \\
\hline Situation no.2 & 45,50, and 55 & $\begin{array}{l}\text { Average velocity, U } \\
(\mathrm{cm} / \mathrm{s})\end{array}$ & 38.58 \\
\hline Situation no.3 & 60,65, and 70 & Flow discharge, Q (lit/s) & 25 \\
\hline $\begin{array}{c}\text { Measurement } \\
\text { levels }(\mathrm{cm})\end{array}$ & $0.5-6.5-11-14-18-22-27$ under the water surface \\
\hline
\end{tabular}

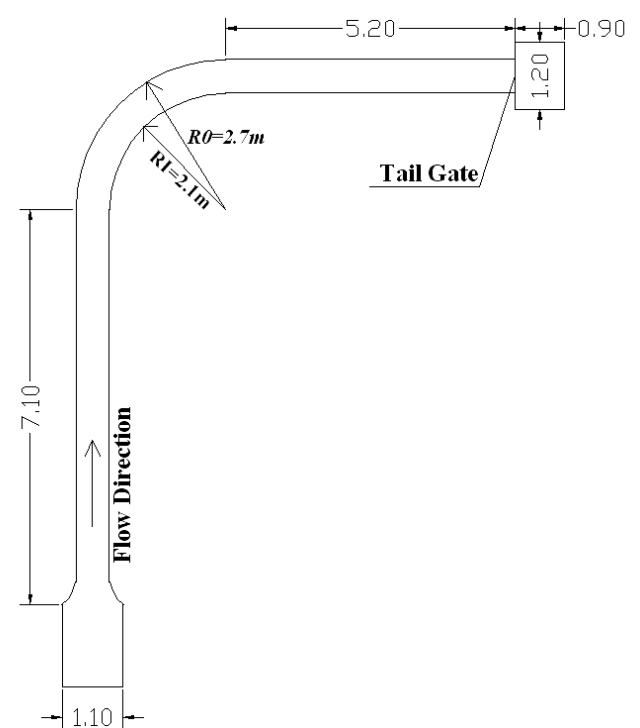

Fig. 1. Schematic view of flume.

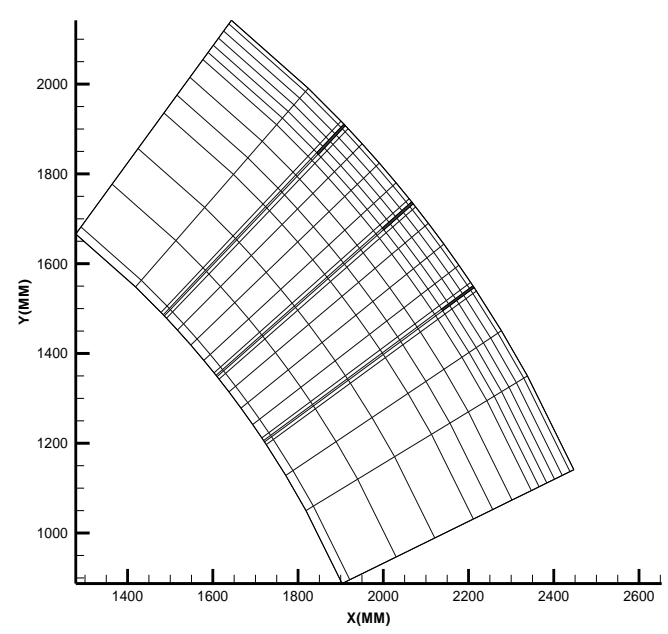

Fig. 2. Mesh generation of calculated velocity.

Depth - Time Graph

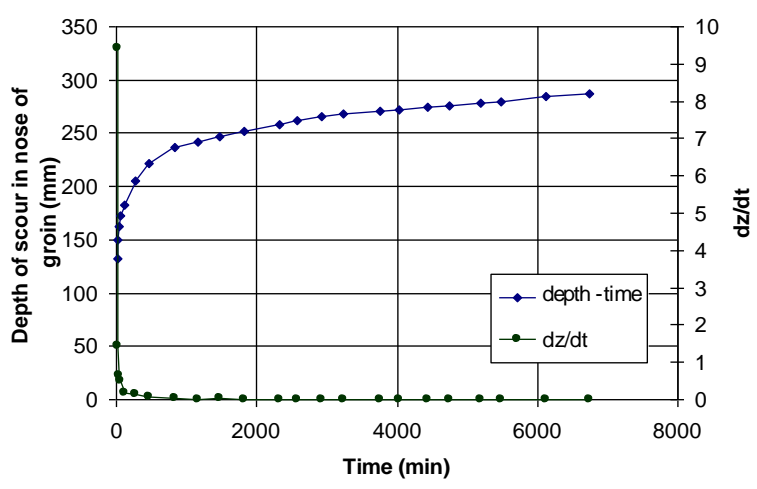

Fig. 3. Time development.

\section{RESULT AND ANALYSIS}

\section{A. Evaluation of Equilibrium Time}

For choosing equilibrium time for critical scouring condition and regarding initial prospecting for setting up spur dike in 3 different positions, experiments with different discharges and hydraulically condition $0.9<U / U c<1$ have been done. Results of these experiments indicated that the maximum scour depth occurred in position $75^{\circ}$ of bend. For 
getting better result in this position and same situation long time experiment (114 hours) has been done. Maximum scour depth versa time for this experiment shows in Fig. 3. In this figure also variations of $d z / d t$ have been drawn. Where $\mathrm{dz}$ is scour depth variation and $\mathrm{dt}$ is time variation.

All experiments were conducted until the quasi equilibrium condition was reached. The equilibrium is carried out for 114 hours but as the time development shows in Fig. 3, 85 percentage of scouring occurs in 25 hours, therefore, 25 hours is selected as quasi equilibrium condition. As shown in Fig. (3), this time approximately is equivalent with time that variation of $d z / d t$ tends to zero.

\section{B. Flow Pattern Vicinity of Three Spur Dike}

1) Flow pattern vicinity of three spur dikes located in $30^{\circ}$, $35^{\circ}$, and $40^{\circ}$

In this study, behavior of flow pattern in vicinity of three spur dikes investigated in four sections: (1) upstream of first spur dike, (2) region between first and second spur dike, (3) between second and third spur dike, and (4) downstream of third spur dike. Fig. 4 shows flow pattern in position $30^{\circ}, 35^{\circ}$, and $40^{\circ}$ of spur dikes. These four phenomena play an important role in behavior of flow pattern: 1-flow separation, 2- down flow, 3-up flow, and 4- reverse flow. Flow separation is clear occurred upstream of fist spur dike in Fig. 4. Beginning location of this separation is occurred approximately at 0.78 times the spur dike length in the upstream of first spur dike.

In region between first and second spur dike, flow in first elevation extracts from second spur dike and tends to fist one. This behavior occurred because of down flow, then down flow change to up flow whenever down flow contact to second spur dike. This phenomena cause to create vertical vortex with opposite side of secondary flow, therefore the flow deviation and disturbance of secondary flow occurred in vicinity of the region. As well, near the water surface, down flow occurred at upstream of second spur dike. In restricted area of second spur dike two vertical vortexes created which the first one contains the main section of flow and it is up flow and another one is down flow. Results showed that by increasing the depth of flow the central of vortex tends to first spur dike. Vortex center in second layer is located vicinity of second spur dike, and in sixth layer is approached to the wall of first spur dike. It is clear that the direction of stream flow in restricted area of two spur dikes occurred from second one to first one. On the other hand, a reverse flow took place between the two spur dikes which caused the central of vortex be transferred from second spur dike to first spur dike. Behavior of flow in region of second and third spur dikes was completely different from the behavior of flow in region of first and second spur dikes. The flow tends to return in restricted area of first and second spur dike after passes from the seconds spur dike. It can be concluded that the flow of restricted area of second spur dike influences in first one when three spur dikes are located $5^{\circ}$ distance to each other (Fig. 5).

In fourth level the behavior of flow is like third level with the conflict that the central of vortex moved to third spur dike from the second spur dike because of reverse flow. Flow pattern in fifth level consist of two distinct vortexes, one is occurred vicinity of third spur dike with small dimension and another one vicinity of second spur dike with large dimension. Behavior of flow pattern in downstream of third spur dike consists of reverse flow in lower level. Therefore the intense and dimension of vortex in third spur dike decreases rather than other spur dikes.

Fig. 6 shows the value of the velocity resultant around three spur dikes which is located in degree of $30^{\circ}, 35^{\circ}$, and $40^{\circ}$. As is shown in this figure, the path of maximum velocity of flow is continued till $47.5^{\circ}$ because of secondary flow.

\section{2) Flow pattern vicinity of three spur dikes located in $45^{\circ}$, $50^{\circ}$, and $55^{\circ}$}

Behavior of flow around three spur dikes in second situation is shown in Fig. 7. The behavior of flow at up stream of first spur dike is like previous situation with the difference that the beginning location of flow separation is occurred 1.43 times the spur dike length at upstream of first spur dike. Therefore, as the spur dike replaced to the end of bend the beginning location of flow separation increases from the first spur dike, because the secondary flow is occurred in the bend and transfer flow momentum. As the flow momentum transfer, the maximum velocity tends to outer wall, thus it can be concluded that by replacement of spur dike to the end of the bend, the impact velocity of flow to the first spur dike increases and cause large dimension of vortex be created. Behavior of flow pattern in restricted area of first and second spur dike is almost similar to previous situation. In addition, intensity of flow rotation in second position is greater than first position and other obvious behaviors of flow are like the last situation.
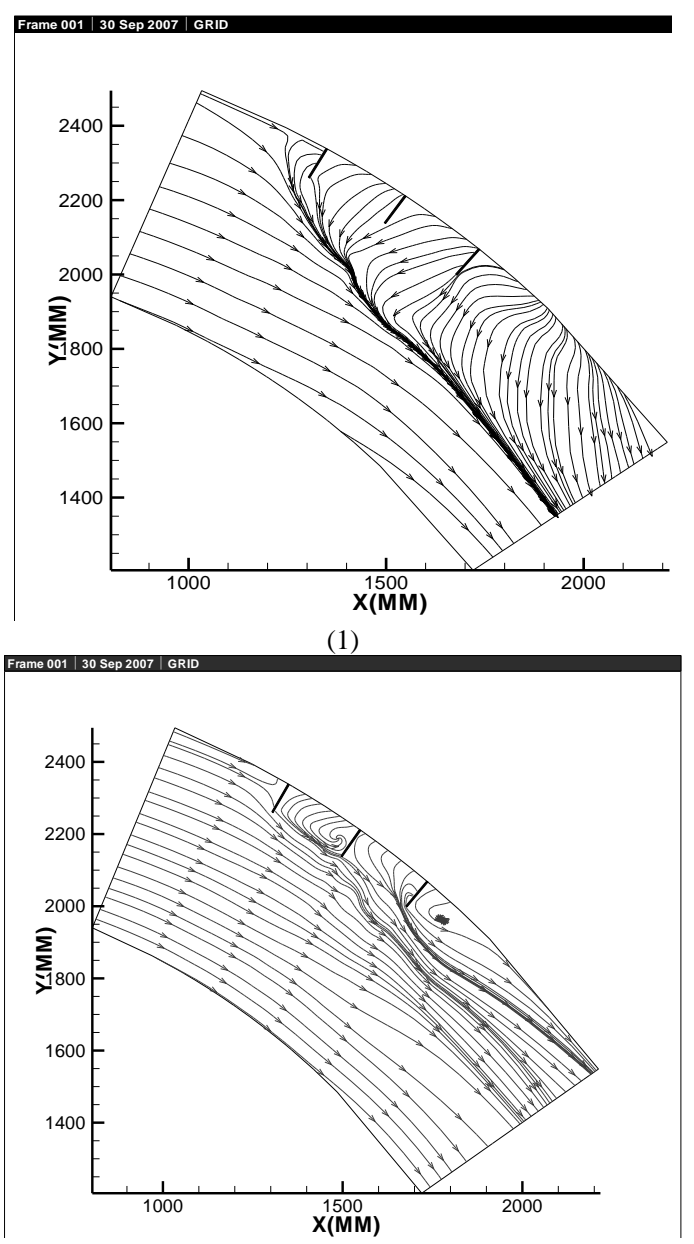

(2) 

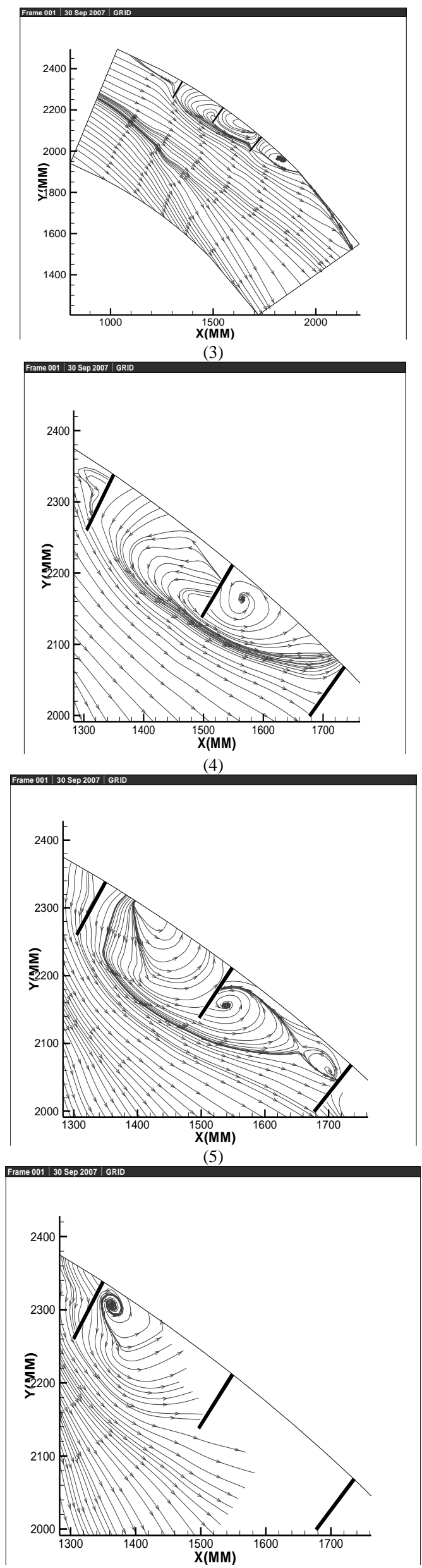

(6)

Fig. 4. Flow pattern around three spur dikes situated in 30,35 and 40 degrees1) $1^{\text {st }}$ 2) $2^{\text {nd }}$ 3) $3^{\text {rd }}$, 4) $4^{\text {th }}$, 5) $5^{\text {th }}$, and 6) $6^{\text {th }}$ elevations.

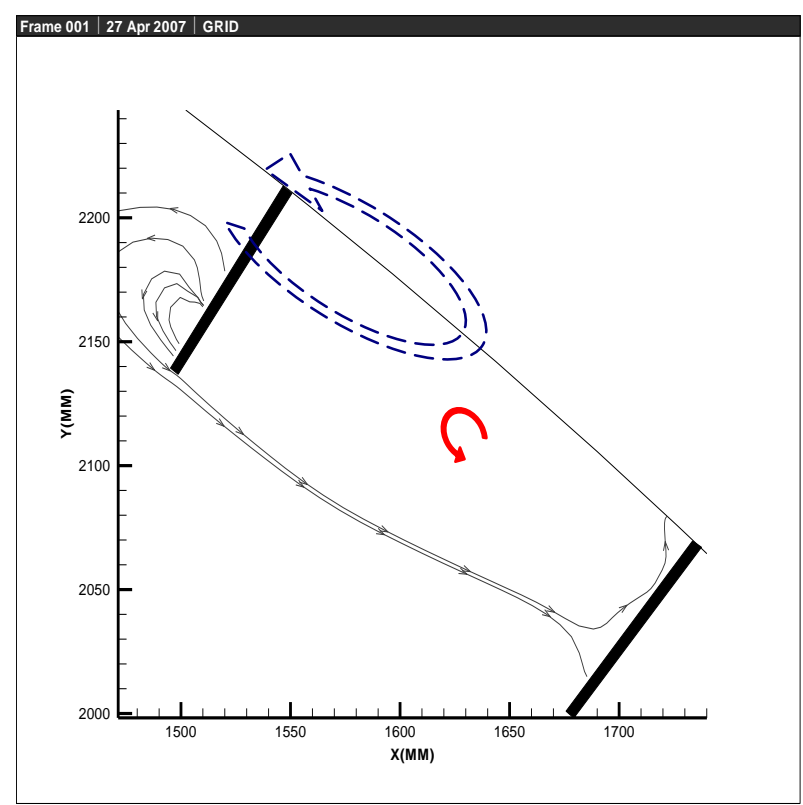

Fig. 5. Flow behavior between $2^{\text {nd }}$ and $3^{\text {rd }}$ spur dike at $3^{\text {rd }}$ level.

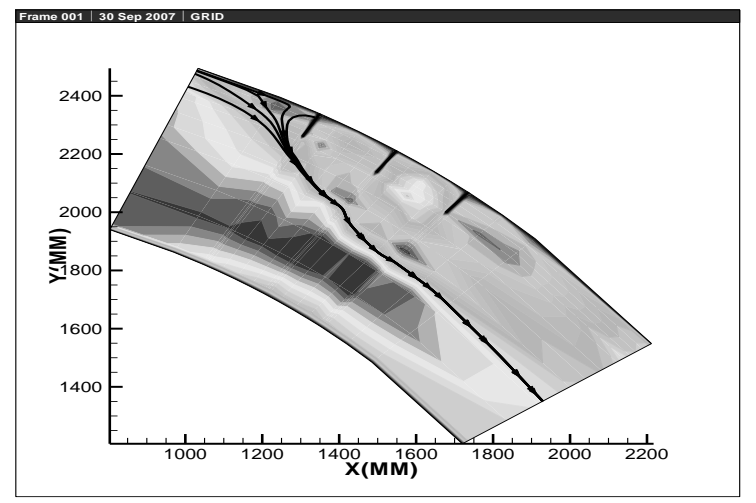

Fig. 6. Velocity component (u) in vicinity of spur dikes.

3) Flow pattern vicinity of three spur dikes located in $60^{\circ}$, $65^{\circ}$, and $70^{\circ}$

Behavior of flow around the three spur dikes in position $60^{\circ}$, $65^{\circ}$, and $70^{\circ}$ situation is shown in Fig. 8 and 9. The beginning location of flow separation is occurred 2.61 times the spur dike length at upstream of first spur dike. In restricted area between first and second spur dike only one vortex was created (Fig. 8) witch its center tends to first spur dike when the water depth increases. Flow pattern in third restricted area are completely similar to both previous situations. The comparison of Figures 5 and 8, and results of velocity quantities around three spur dikes at $1^{\text {st }}$ level shows that the boundary of separation zone tends to outer bend when the spur dikes towards to the end of bend. As it was noted before, by replacing the spur dikes toward to end of bend, the velocity increases. Therefore, the zone of flow separation in first situation consist a larger dimension rather than other situation. In addition, by replacing the spur dikes toward to end of bend, the maximum velocity decreases.

C. Compare of Flow Pattern Characteristic of Three Spur Dikes with $5^{\circ}$ Distance in Three Different Positions

1) Compare of separation flow characteristics

Details of separation flow for three spur dikes in different position are shown in Table II and III. In these tables, length and width of separation zone are shown in dimensionless form 
with length of spur dike. According to this table, by changing from first situation to third one, the length of separation zone decreases, but the width of separation zone remains almost constant.

\section{2) Compare of bed shear stress}

For calculating of shear stress Tingsanchali (1983) equation has been used which is shown below:

$$
\begin{gathered}
\tau=C_{f} \cdot \rho \cdot\left(\bar{u}^{2}+\bar{v}^{2}\right) \\
C_{f}=\frac{n^{2} g}{h^{\frac{1}{3}}} \\
n=\frac{d_{50} 1 / 6}{21.1}
\end{gathered}
$$

In which, $\tau=$ bed shear stress, $\bar{u}=$ average velocity in flow direction, $\bar{v}=$ average velocity perpendicular to flow direction, $n=$ manning coefficient, $h=$ depth of water, and $g=$ gravity acceleration.

Results showed that the value of shear stress in vicinity of third spur dike is more than other spur dikes (Fig. 10). According to the Fig. 10 the vortexes occur in reign of first and second spur dike, therefore energy dissipation is occurred in this zone thus the velocity components are decreased. By decreasing the velocity components, the bed shear stress decreases.

\begin{tabular}{|c|c|c|c|c|}
\hline & \multirow{2}{*}{$\begin{array}{l}\text { Place of flow } \\
\text { separation } \\
\text { (degree) }\end{array}$} & \multicolumn{3}{|c|}{$\begin{array}{l}\text { Length Dimensionless of } \\
\text { separation zone }\end{array}$} \\
\hline & & Third level & Fourth level & Fifth level \\
\hline $\begin{array}{l}\text { First } \\
\text { position }\end{array}$ & $\begin{array}{l}1.25^{\circ} \text { before } \\
\text { spur dike }\end{array}$ & 3.6 & 1.33 & - \\
\hline $\begin{array}{l}\text { Second } \\
\text { position }\end{array}$ & $\begin{array}{l}2.75^{\circ} \text { before } \\
\text { spur dike }\end{array}$ & 3.58 & 3.44 & - \\
\hline $\begin{array}{l}\text { Third } \\
\text { position }\end{array}$ & $\begin{array}{l}5^{\circ} \text { before } \\
\text { spur dike }\end{array}$ & 3.5 & 3.3 & - \\
\hline
\end{tabular}

TABLE II: DETAILS OF Flow SEPARATION AROUND THREE SPUR DIKE IN THREE DIFFERENT POSITIONS EXPERIMENTS CHARACTERISTICS

\begin{tabular}{|c|c|c|c|c|}
\hline & \multirow{2}{*}{$\begin{array}{l}\text { Place of flow } \\
\text { separation } \\
\text { (degree) }\end{array}$} & \multicolumn{3}{|c|}{$\begin{array}{l}\text { Width Dimensionless of } \\
\text { separation zone }\end{array}$} \\
\hline & & Third level & Fourth level & $\begin{array}{l}\text { Fifth } \\
\text { level }\end{array}$ \\
\hline $\begin{array}{l}\text { First } \\
\text { position }\end{array}$ & $\begin{array}{l}1.25^{\circ} \text { before } \\
\text { spur dike }\end{array}$ & 1.44 & 1.48 & 1.57 \\
\hline $\begin{array}{l}\text { Second } \\
\text { position }\end{array}$ & $\begin{array}{l}2.75^{\circ} \text { before } \\
\text { spur dike }\end{array}$ & 1.35 & 1.48 & 1.50 \\
\hline $\begin{array}{l}\text { Third } \\
\text { position }\end{array}$ & $\begin{array}{l}5^{\circ} \text { before spur } \\
\text { dike }\end{array}$ & 1.32 & 1.47 & 1.48 \\
\hline
\end{tabular}

TABLE III: DETAILS OF FLOW SEPARATION AROUND THREE SPUR DIKE IN THREE DIFFERENT POSITIONS
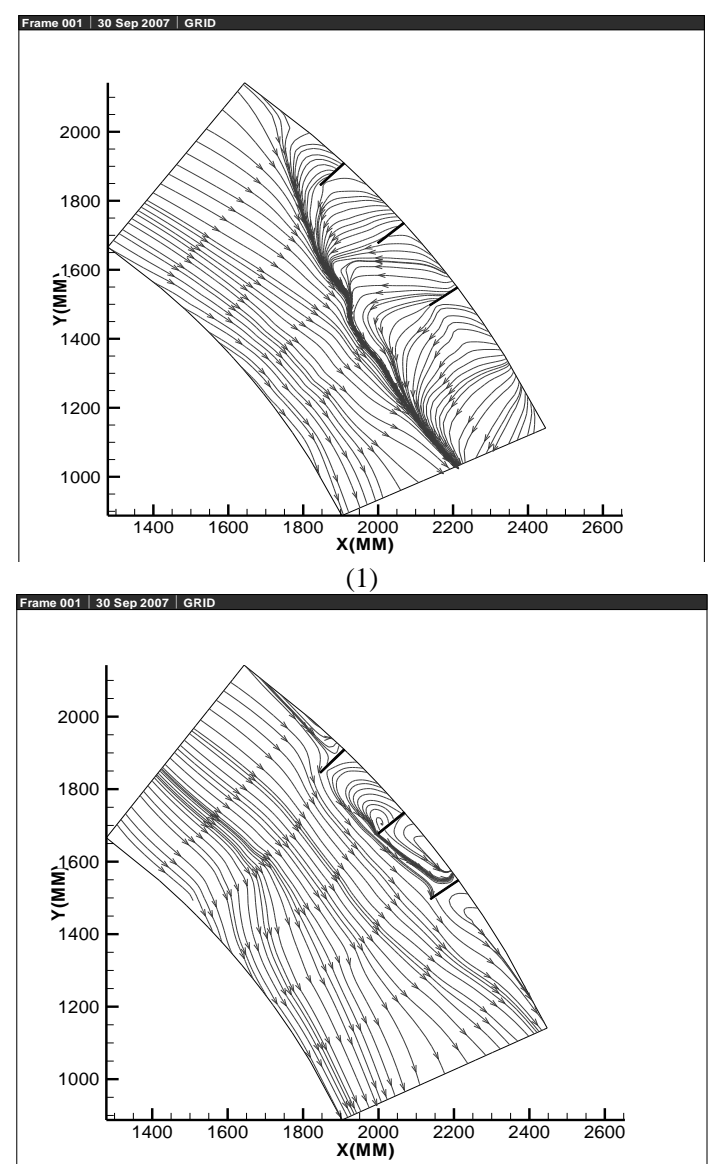

(2)

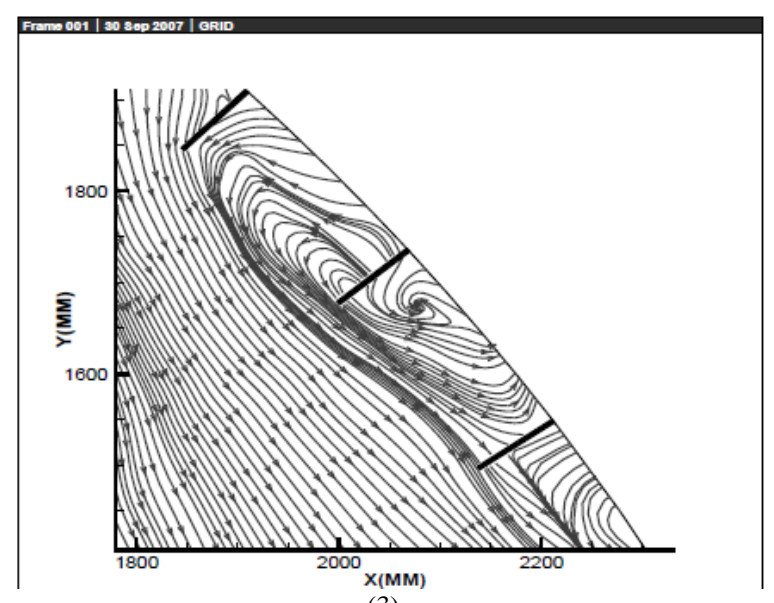

(3)

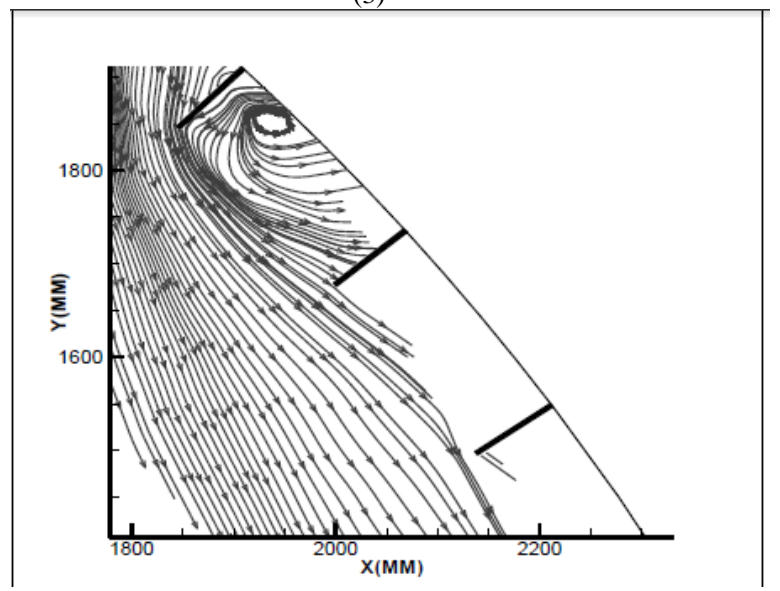

(4)

Fig. 7. Flow pattern around spur dikes situated at 45, 50, and 55 degrees 1 ) $\left.\left.\left.1^{\text {st }}, 2\right) 3^{\text {rd }}, 3\right) 4^{\text {th }}, 4\right) 6^{\text {th }}$ level. 


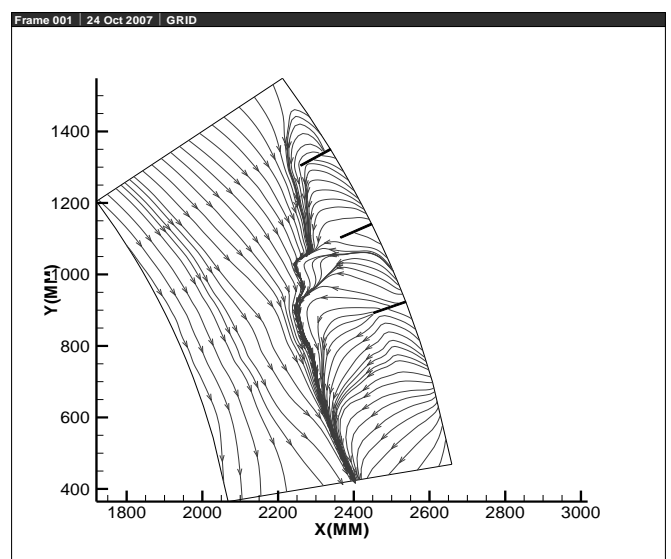

Fig. 8. Flow patterns around three spur dikes at $3^{\text {rd }}$ situation, $1^{\text {st }}$ level.

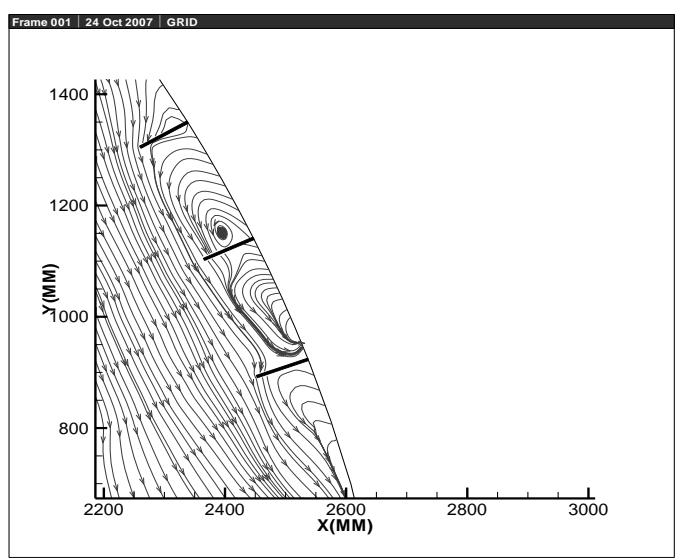

Fig. 9. Flow patterns around three spur dikes at $3^{\text {rd }}$ situation, $3^{\text {rd }}$ level.

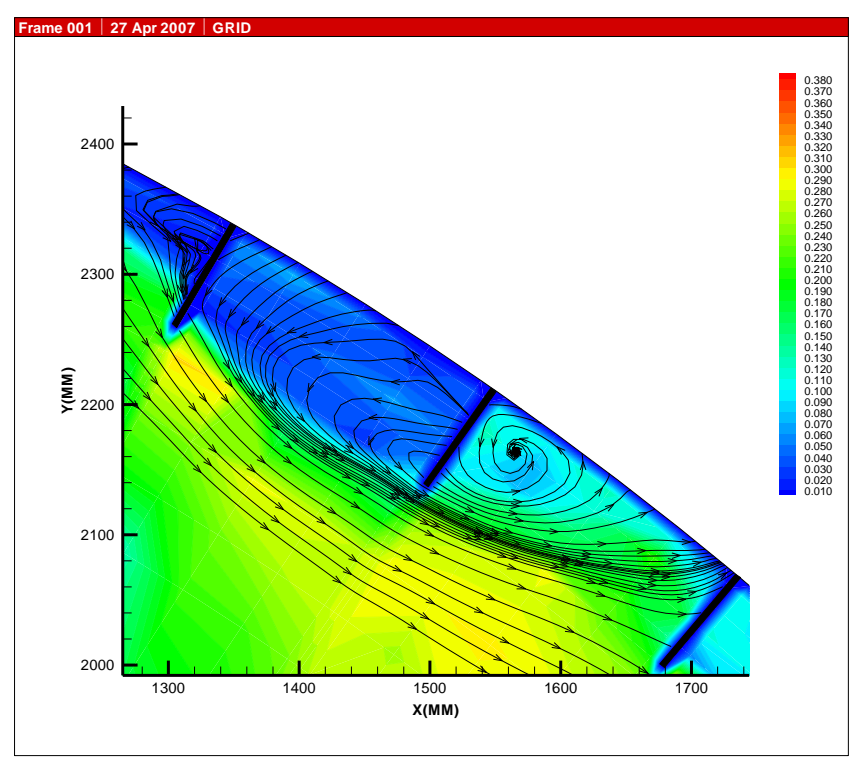

Fig. 10. Flow pattern around three spur dike in position 30,35 , and $45^{\circ}$.

\section{RESULT}

In the present study the flow pattern and stress distribution around three spur dikes in $90^{\circ}$ bend was investigated. By using a $2 \mathrm{D}$ velocimeter, flow field in vicinity of spur dikes in curved channel with sandy bed under a clear water regime was measured. Flow pattern is divided in to four region, upstream of first spur dike, region between first and second spur dike, between second and third spur dike, and downstream of third spur dike. By analyzing experimental data fallowing important results are addressed in present work:

Flow pattern in first region consist of flow separation and down flow. Flow pattern in second region consist of vortex flow which tends to first spur dike by increasing the water level. Flow pattern in third region consist of vortex with different characteristic of pervious vortex and in fourth region flow pattern consist of up flow and return flow.

By increasing the position of spur dikes to the downstream the length of separation zone decreases, and also the width of separation zone remain almost constant.

By increasing the position of spur dikes to the downstream the shear stress increases.

\section{REFERENCES}

[1] T. Tingsanchali and S. Maheswaran, "2-D depth-averaged flow computation near groyne," Journal of Hydraulic Engineering, vol. 116, no. 1, pp. 71-86, 1983.

[2] S. Giri and Y. Shimizu, "Observation on bed variation in a meandering like flume with river training structures," Annual Journal of Hydraulic Engineering, JSCE, vol. 48, pp. 619-624, 2004.

[3] N. Rajaratnam and B. A. Nwachukwu, "Flow near Groyne-like structures," J. Hydr. Engrg, ASCE, vol. 109, no. 3, pp. 463-480, 1983,

[4] A. Molinas, K. Kheireldin, and B. Wu, "Shear stress around vertical wall abutments," Journal of Hydraulic Engineering, pp. 164-175, August 1998.

[5] G. Mousavi, "Scour around a spur dike at a 90 degree bend," presented at $2^{\text {nd }}$ Conference on Scour and Erosion, Singapore, 2004.

[6] M. M. Soliman, K. Attia, M. Kotb, A. M. Talaat, and A. F. Ahmed, "Spur dike effects on the river Nile morphology after high Aswan dam," presented at Congress of the International Association of Hydraulic Research, IAHR, 1997.

[7] Hoseini, "Numerical modeling of flow around spur dikes at 90 degree rigid bed bend," M.Sc. Thesis, Tarbiat Modares Universiy, Tehran, Iran, 2006.

[8] M. Ghodsian, M. Vaghefi, and N. Panahpour, "Experimental investigation of the separation zone around a groyne in the 90 degree bend," presented at 4th National Congress in Civil Engineering, 2007.

[9] M. J. Forghani and M. Godsian, "Experimental study on flow field and scouring around a spur dike in ninety degree bends," $32^{\text {nd }}$ IAHR Congress, Venice, Italy, 2007.

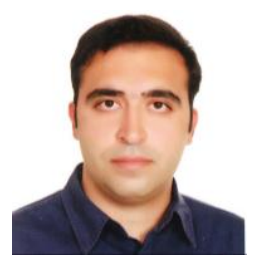

Seyed Amin Salamatian is an assistant professor of Shahab Danesh Institute of Higher Education, Qom, Iran. He finished his Ph.D. in water and hydraulic structure engineering in Amirkabir University of Technology (Tehran Polytechnic), Tehran, Iran. He is interested in flow field and local scour around hydraulic structure, reliability and risk assessment method in engineering design and Protection method against scouring.

$\mathrm{He}$ is also a member of International Association for Hydraulic Research (IAHR). He has work experiences in different civil engineering fields such as Onshore and Offshore structure design, Wave modeling, bridge engineering, river training and hydrodynamic and sediment transport modeling.

Dr. Salamatian is a member of Iran hydraulic Association (IHA) and a reviewer of Journal. 